\title{
Efficacy of a compliant semicircular Ilizarov pin fixator module for treating infected nonunion of the femoral diaphysis
}

\author{
Ashraf A. Khanfour • Mohamed M. El-Sayed
}

Received: 22 June 2013/Accepted: 22 July 2014/Published online: 29 July 2014

(C) The Author(s) 2014. This article is published with open access at Springerlink.com

\begin{abstract}
Percutaneous transosseous Ilizarov wiring, whilst preferred in the tibia because of its unique properties, carries a high risk of complications in the femur. The aim of this work was to evaluate the efficacy of a more patient-friendly semicircular pin external fixator module built up from parts of the Ilizarov fixator components and its use in managing diaphyseal femoral nonunions. A group of 20 patients with infected diaphyseal nonunions of the femur after internal osteosynthesis were included in this study. The mean age of the patients at the time of surgery was 46 years (range 16-60, SD 15.6). The mean morbidity time since the original trauma was 10.2 months (range $6-15$, SD 2.5). All the cases were fixed by the described external fixator module. Bony union with resolution of infection occurred in $18(94.7 \%)$ out of 19 cases after a mean period in the fixator of 11.2 months (range 8-18 SD 2.9). After a mean follow-up period of 3.5 years (range 2-9, SD 2.6), there were 14 excellent, 3 good, 1 fair and 1 poor results from radiological evaluation and 10 excellent, 7 good, 1 fair and 1 poor results from functional assessment. In conclusion, the described semi-circular pin fixator module is patient-friendly and effective in managing infected nonunions of the femoral diaphysis.
\end{abstract}

Keywords Femur · Ilizarov · External fixation · Infective nonunion $\cdot$ Compliant

\footnotetext{
A. A. Khanfour $(\bowtie)$

Department of Orthopaedic Surgery, Damanhur National

Medical Institute, Damanhur, Egypt

e-mail: Dr_ashrafkhanfour@hotmail.com

M. M. El-Sayed

Department of Orthopaedic Surgery, Tanta University, Tanta, Egypt
}

\section{Introduction}

A locked intramedullary nail is considered the method of choice for treating diaphyseal femoral fractures but is contraindicated in the presence of a concurrent or previous infection [1-5]. The percutaneously applied transosseous Ilizarov external fixator can be adopted for treating these cases, but there are disadvantages in patient compliance and interference with local anatomy [6]. These factors relate to a high risk of injury to the neurovascular structures during percutaneous transosseous wiring and tissue transfixation. Additionally, the application of the complete rings encircling the medial aspect of the patient's thigh causes a major hindrance to a patient's daily activities including personal hygiene [5, 7-13]. For these reasons, a classic Ilizarov fixator using tension wires in the proximal femoral segment is not popular [12, 14] leading to, in 1986, Italian surgeons Catagni and Cattaneo introducing the hybrid modification of using half-pins but maintaining all wires in the distal femur $[11,12]$. This assembly has undergone many modifications including the introduction of concepts of a "dummy ring" and a more stable "delta" distal Schanz pin configuration (Fig. 1). Despite this, patient acceptance remains a major drawback $[10,12,15-17]$.

This work evaluates the efficacy of a more patientacceptable semicircular external fixator module built up from parts of the Ilizarov fixator components for managing diaphyseal femoral fractures.

\section{Patients and methods}

A consecutive cohort of 20 patients with infected diaphyseal nonunions of the femur (after previously unsuccessful internal osteosynthesis) was treated using the semicircular 
Fig. 1 A hybrid Ilizarov external fixator of the femur with a dummy ring (an empty ring without fixation to the bone. It is secured in the middle of the frame and acts as a force transmitter. It will effectively shorten the lengths of the rods and increases the stability of the frame) and the distal delta configuration

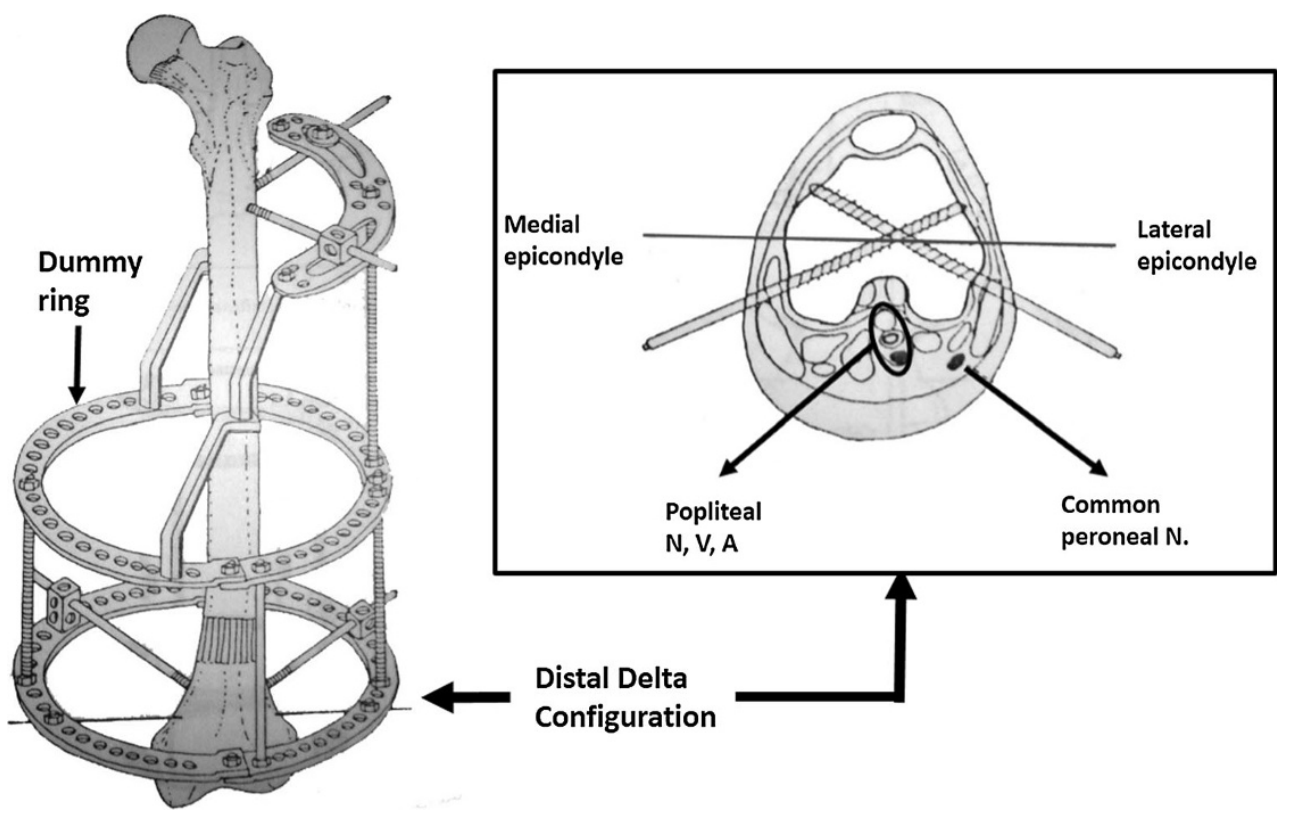

fixator. The patients presented between January 2003 and February 2010. The study was approved by the local ethical committee (General Organization of Teaching Hospitals and Institutes Research Ethical Committee) and was conducted in accordance with the Declaration of Helsinki and Ethical Guidelines for Epidemiological Research (2008). Informed written consent was obtained from all patients and their guardians before participation in the study.

The presence of a nonunion was established clinically: the ability to induce motion at the fracture site; deep tenderness; deformity; and inability to bear weight. Using radiographs, the diagnosis was supported by the presence of a radiolucent gap at the fracture site, sealing off of the medullary cavity, sclerosis of the fractured bone edges or absence of bridging callus after 6 months of the fracture event with evidence of loosening of the implant. The diagnosis was made also if the fracture showed no progressive radiological signs of healing on three successive months.

Infection was suspected clinically by the presence of local pain out of proportion to the nonunion, erythema, swelling and induration with or without chronic draining sinuses. Further evidence was obtained through investigations, which added to a high probability of sepsis: a raised $\mathrm{CBC}$, ESR; the presence of sequestrum, involucrum, periosteal and endosteal new bone formation, cortical irregularities and visible resorption, especially around the osteosynthesis implant on X-rays.

The inclusion criteria were cases with an established infected nonunion of the femoral diaphysis after internal fixation. The exclusion criteria were very obese patients with a large thigh diameter rendering the half-pin offset to

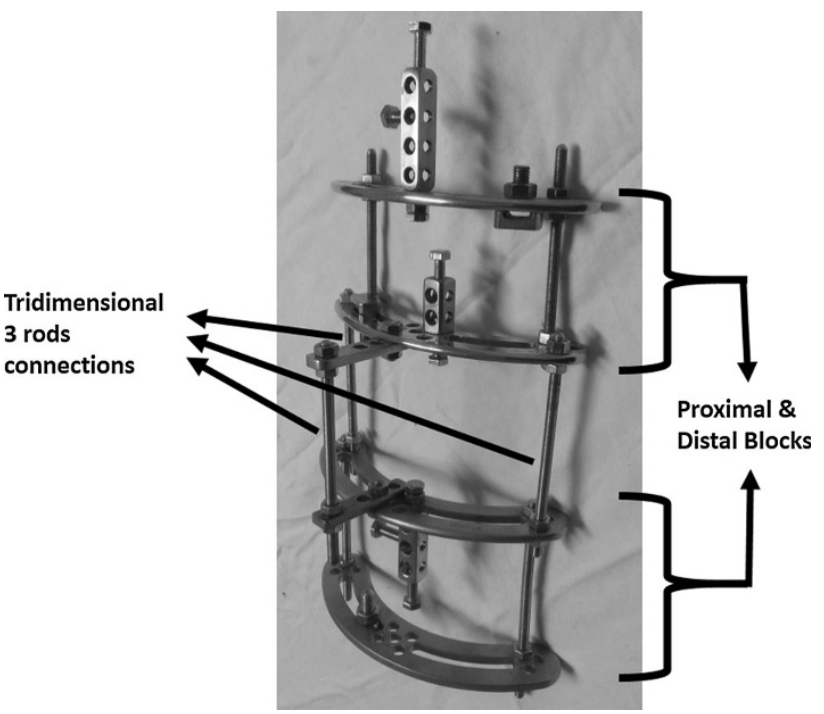

Fig. 2 The semicircular femoral Ilizarov pin fixator module used

be unacceptably long, an insensate limb and noncompliant patients.

The construct (Fig. 2)

The frame was composed of two blocks. Each block comprised two identical femoral arches connected as a pair and to which pin clamps or Rancho cubes were fixed as required. The two blocks were connected by three threaded rods in which the middle rod was lateralised by the aid of two straight plates connected orthogonally to the middle of these arches to add to the multiplanar stability of the frame (Fig. 2). The length of the entire fixator covered the whole 


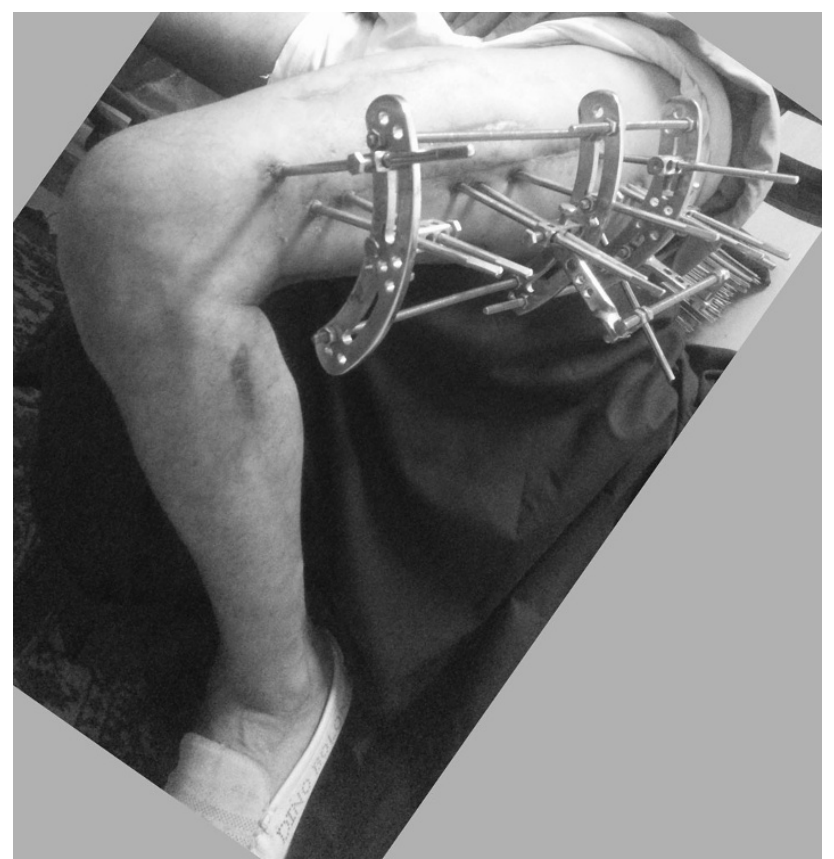

Fig. 3 This photograph shows the divergence and the spread of the pins across the femur. It also demonstrates the ability of the patient to bend his knee freely beyond 90

length of the femur. Six millimetre diameter Schanz halfpins were used mainly with the smaller $5 \mathrm{~mm}$ pins for smaller diameter femurs.

\section{Operative technique}

The construct was assembled pre-operatively. A radiolucent table was used, and a pillow placed to support the ipsilateral buttock of the patient in the supine position. A first surgical strategy was to deal with the infected nonunion: a lateral approach, taking deep samples for culture and sensitivity, extraction of the implants and aggressive debridement of all devitalised soft tissue and bone. The bone ends were cut back square until punctate bleeding was clearly evident, and this followed by lavage with normal saline. The nonunion site was prepared for bone grafting by fish scaling (cortical flaps) and multiple drill holes. If the knee was mobile, the fixator was applied with the knee flexed to $90^{\circ}$ at the end of a radiolucent operating table to ensure the quadriceps were transfixed in flexion by the pins. The fixator was applied orthogonally to the femur by first inserting a $6 \mathrm{~mm}$ diameter Schanz screw $(5 \mathrm{~mm}$ in small diameter femurs) reference pin at the subtrochanteric level near the lesser trochanter, perpendicular to the bone and in the coronal plane. The pre-assembled proximal block was fixed to this reference pin, and further pins added to hold the proximal segment securely. With an assistant holding the reduction of the newly prepared bone ends,

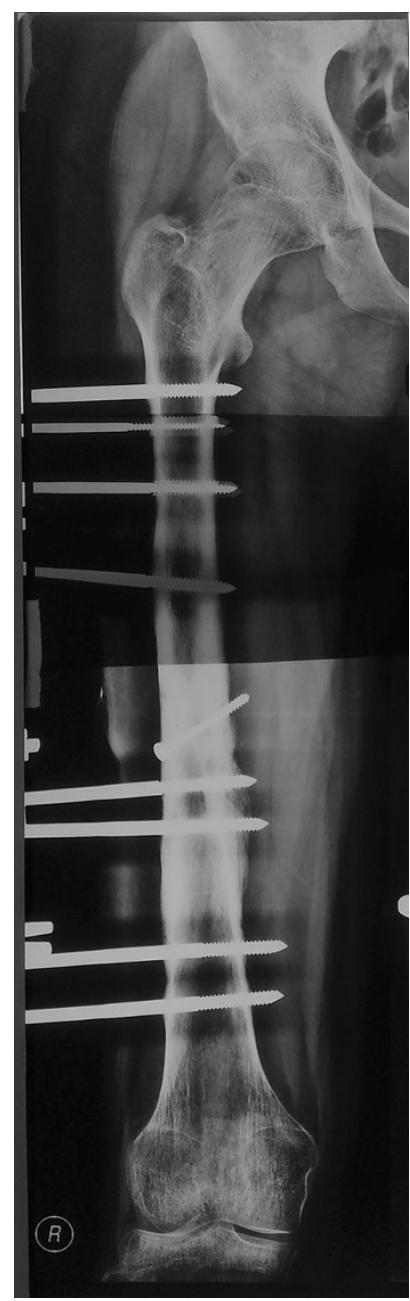

Fig. 4 Case no. 1 in table I. A-P view X-ray showing infected nonunion with a spiral fracture configuration at the mid shaft right femur fixed by the described semicircular Ilizarov pin fixator module augmented by an interfragmentary cortical screw

fixation of the distal fragment to the fixator was then carried out. At the completion of fixation, each segment had at least three to four pins in different planes with as much of a divergence angle in between as possible (Fig. 3). The fixation pins were at least $3 \mathrm{~cm}$ from the fracture site. Augmentative interfragmentary screw fixation was needed for one case (Fig. 4). Structural iliac bone grafts were used in seven cases that were fixed with a screw (Fig. 5). Iliac bone chips were used in two cases to stimulate healing. Two cases needed repeat bone grafting, one after 9 months and the other after 10 months to stimulate healing. In none of the cases was simultaneous bone lengthening performed.

The patient was discharged on the second or third postoperative day. Early assisted weight-bearing and continual knee exercises were encouraged. Antibiotics were prescribed according to culture and sensitivity results from deep samples submitted and were for 2 weeks after 


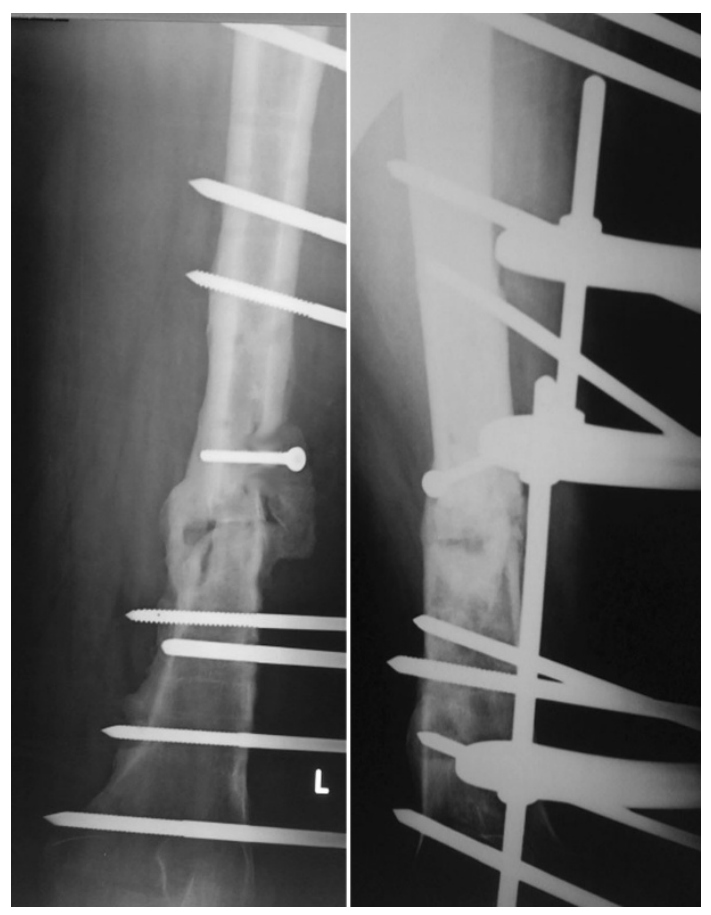

Fig. 5 Case no. 8 in table I. Illustrates an augmentative structural iliac bone graft that was securely fixed by a cortical screw. Union of the femoral fracture was achieved after incorporation of the strut graft

resolution of clinical signs of infection. Follow-up X-rays were obtained every month for the first 3 months, thereafter every 2 months until union and removal of the fixator. Frequent compression of the fracture site was needed if osteolysis at the fracture site was noted. Union was declared through observing bridging callus on anteroposterior, lateral and oblique views; this was confirmed clinically by dynamising the fixator and observing the ability of the patient to walk and perform a single-leg stance on the affected limb without pain, instability or deformation at the fracture site. The fixator was removed in the operating room under general anaesthesia.

Outcome was determined using a combination of radiological and functional criteria. The classification system by Paley and Maar [18, 19] was used. This is based on the presence or absence of each of these five criteria: union; infection; deformity in any plane $>5^{\circ}$; limb length discrepancy $>2.5 \mathrm{~cm}$; and a weak cross-sectional area at the union site that requires long-term bracing or protection. An excellent bone result was assigned for those who achieved full union and resolution of infection with absence of the other three factors. A good bone result was as excellent with the presence of one of the other three criteria. A fair bone result was as excellent with the presence of two of the other criteria. A poor bone result was a persistent nonunion with or without persistent or recurrent bone infection.
Additional outcome reporting used a modification of the system derived from Paley and Maar in 2000 and Barbarossa $\mathrm{V}$ et al. in $2001[19,20]$. This was based on five criteria: the ability for normal daily activities and a return to work; pain; the need for walking aids or braces; a loss of more than $20^{\circ}$ of knee range of motion from the preoperative levels; and soft tissue dystrophy. An excellent result was assigned for those with full activity, and the other four criteria were absent. A good result was deemed if the patient was active with mild or no pain, and one of the other three criteria present. A fair result was declared if the patient was active with mild or no pain, and two of the other criteria present. A poor occurred if the patient had markedly limited activity regardless of the presence of other criteria, any patient with significant pain (requiring narcotics) or a patient with three of the other criteria.

\section{Results}

The mean age of patients at the time of surgery was 46 years (range 16-60, SD 15.6), 16 (80\%) were male and $4(20 \%)$ were females. The mean period since the original trauma was 10.2 months (range 6-15, SD 2.5). A history of road traffic accident was noted in 18 patients; one patient fractured after a fall (case no. 10), and one had a gunshot injury (case no. 7). Eighteen were initially closed fractures, and one was an open fracture grade II (Gustilo and Anderson Classification). The mean number of previous operative procedures was 3 ; these included repeated debridement, plating, intramedullary nailing, gentamicin bead implantation and external fixation. Four patients were diabetic and 1 positive for hepatitis C. One patient had ipsilateral anterior poliomyelitis of the lower limb.

Eleven patients presented with a stiff knee in extension. Eighteen had minor shortening $<2 \mathrm{~cm}$, whilst two patients presented with 3 and $2.5 \mathrm{~cm}$ shortening (cases no. 4 and 9), respectively. Five cases presented with $>1 / 3$ circumferential cortical defect (cases no. 2, 7-9, 13, 15, 18; Table 1).

The mean period spent in the fixator was 11 months (range 8-18, SD 2.9). After a mean follow-up period of 3.5 years (range 2-9, SD 2.6), bony union without recurrence of infection was noted in 18 out of 19 patients (94.7\%) who attended the final follow-up (Fig. 6). The patient lost to follow-up (case no. 12 in the table) was a 59-year-old diabetic male with an infected midshaft nonunion of the femur with two previous episodes of plate fixation. He was treated in the fixator for 8 months and then lost to follow-up.

Using the bony criteria, there were 14 excellent, 3 good, 1 fair and 1 poor result. Despite the inevitable shortening of the limb from freshening and squaring off the nonunion 


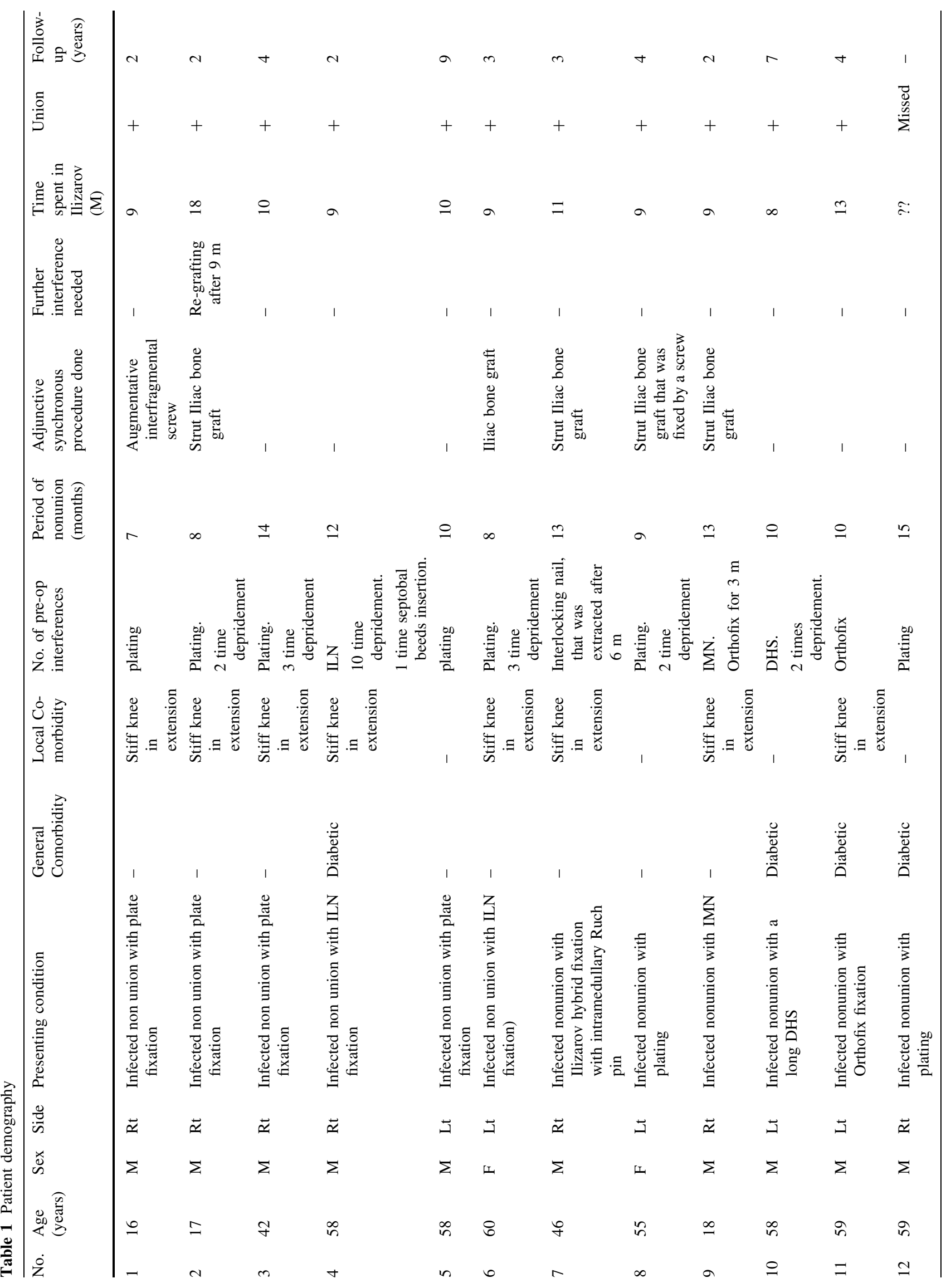




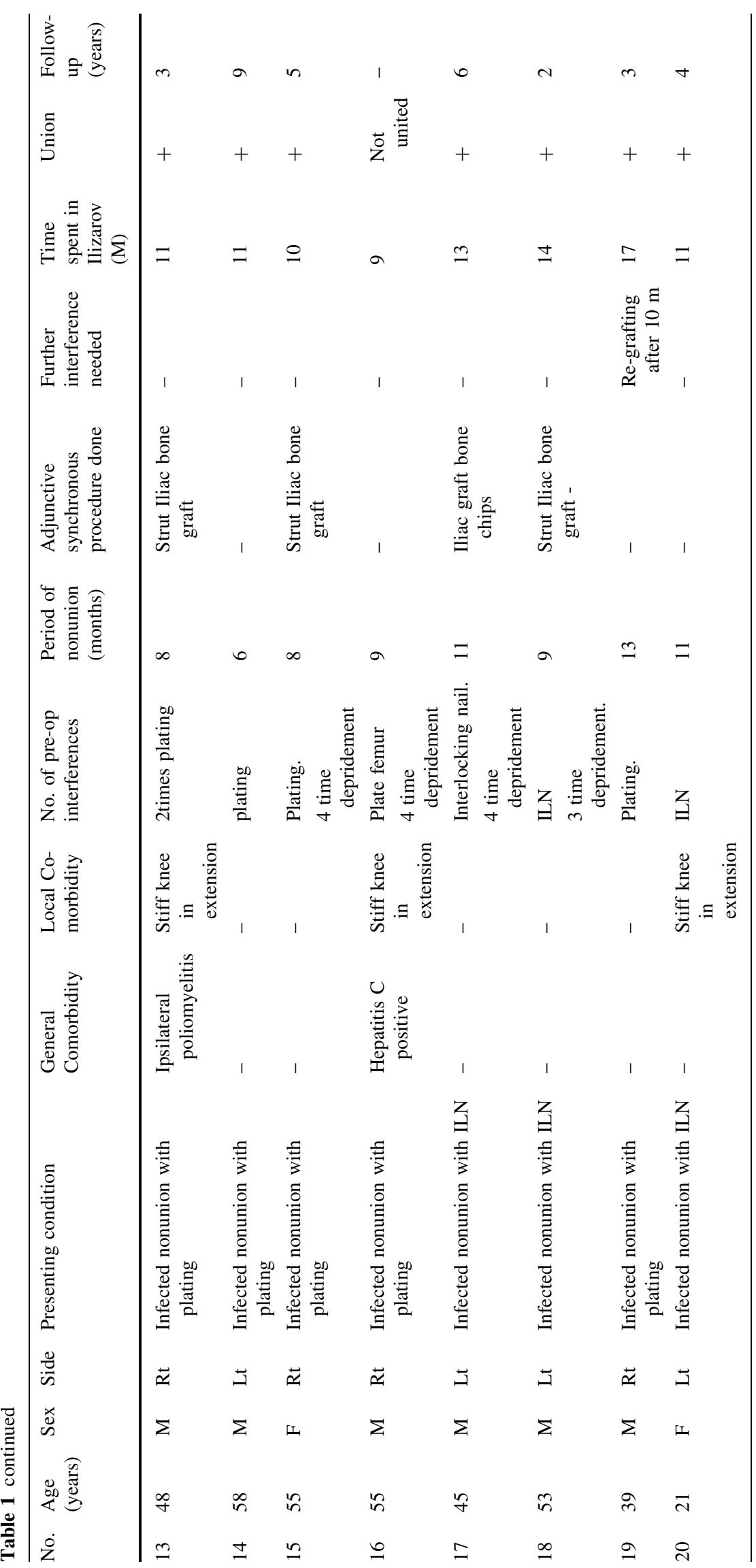



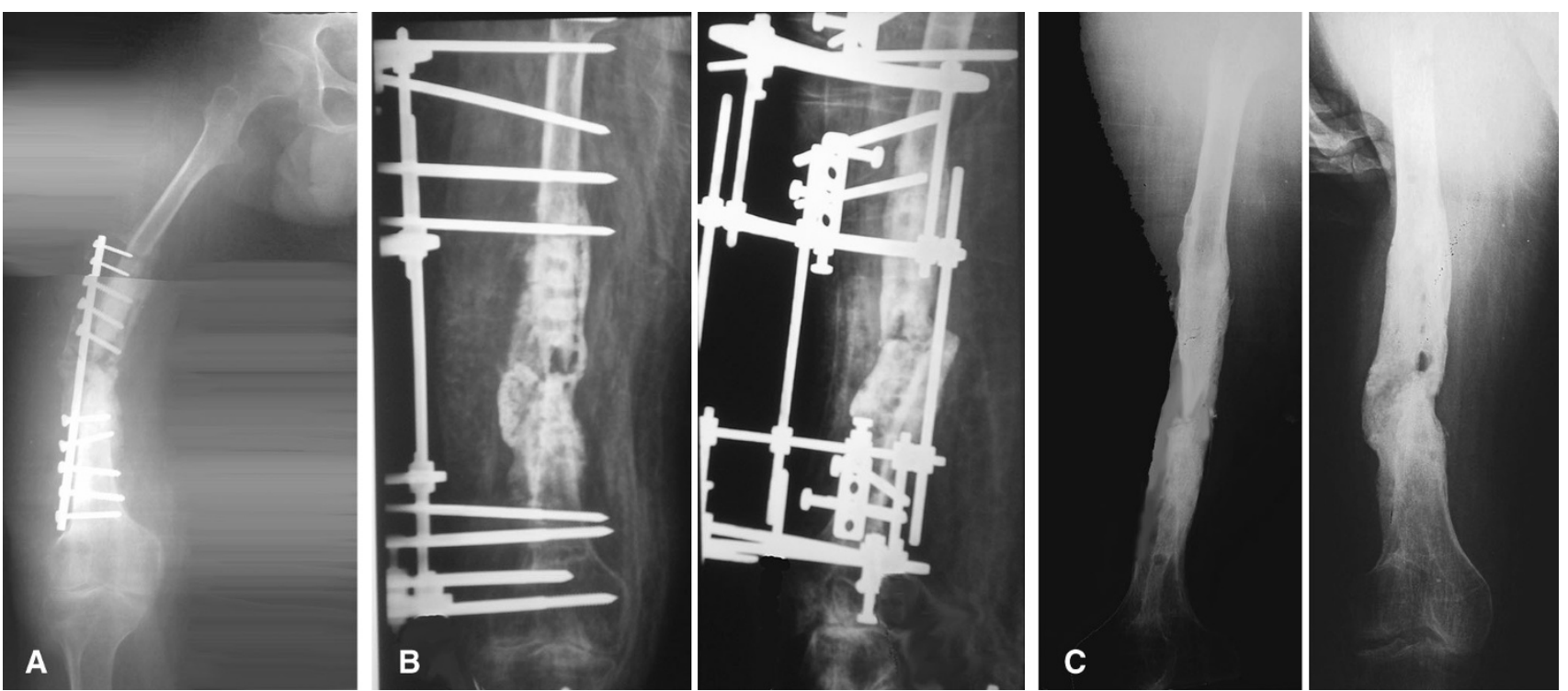

Fig. 6 a-c Case no. 13 in table I. a A-P view of showing infected nonunion of the midshaft femur with periosteal and endosteal new bone formation, cortical irregularities and visible resorption, especially around the plate and screws with loosening of the fixation.

bone ends, only two patients showed significant shortening $>2.5 \mathrm{~cm}$ (cases no. 4 and 9 with 5 and $4 \mathrm{~cm}$, respectively) but were also the cases who presented initially with 3 and $2.5 \mathrm{~cm}$ shortening. The poor result (case no. 16 in the table) was a 55-year-old male with infected nonunion fracture of the upper to mid third right femoral shaft after previous plating. He was positive for hepatitis $\mathrm{C}$ infection with a stiff knee in extension. After 9 months in the fixator, he refused to continue with treatment and asked for removal of the fixator and substitution with an ischial weight-bearing orthosis. Using functional criteria, there were 10 excellent, 7 good, 1 fair and 1 poor result (Table 2).

During the period of external fixation, patients noted easier compliance with this fixator in carrying out their physiological daily activities, personal hygiene, sitting or lying down. All patients had one or more pin track infections that were resolved by local dressing and systemic antibiotics. There were bouts of pain, oedema and reactive depression, all of which resolved after completion of treatment. A refracture occurred in one patient 2 years after completion of treatment following new trauma and was managed by the same fixator; this united after 8 months. Of the eleven patients who presented with stiff knees in extension, none showed any noticeable improvement at the end of follow-up. For those patients who developed loss of knee motion during the period of fixation, this was noted to improve by the end of follow-up with the exception of three cases (Table 2). b Postoperative A-P and lateral X-rays with the fixator. c Follow-up $\mathrm{X}$-rays after 3 years. This was classed an excellent result from both bony and functional outcomes

\section{Discussion}

When external fixation is indicated, a balance between the desirable characteristics of the fixator assembly and patient tolerability is important $[7,21]$. Biomechanically and in the femur, unilateral fixators are weaker in bending, axial and torsional stability. In contrast, ring fixators give excellent three-dimensional stability but at the expense of the patient comfort. Even in a hybrid fixator, the distal transfixing wires (apart from being difficult to tolerate) are not sufficiently rigid against bending forces in the sagittal plane as the permitted safe corridor for insertion is narrow and located mainly in the frontal plane [7, 22].

Factors which determine the stiffness of a fixator construct depend on its two main constituents: the device material and configuration on one hand and the pins on the other. Fixator rigidity is directly proportion to pin stiffness that is increased by: firstly improving material properties; secondly by increasing pin diameter-but not to exceed one-third of the bone diameter-and thirdly a decreased pin offset (the free bending length of pins which is the distance between the bone surface and the external pin clamp). Other pin factors that add to fixator rigidity are increased pin spread (length of the fractured bone involved in fixation), increased pin numbers and levels and lastly, increased pin divergent angle in the axial plane [7, 11, 2125]. Considering the aforementioned factors, the design of the external fixator used in this study can be considered as a modification of the Catagni and Cattaneo module in 1986 
Table 2 Bone and functional results

\begin{tabular}{|c|c|c|}
\hline No. & Bone results & Functional results \\
\hline 1 & $\mathrm{G}$ (Frontal plane varus $\left.8^{\circ}\right)$ & $\mathrm{E}$ \\
\hline 2 & $\begin{array}{l}\text { F (Weak union site cross- } \\
\text { sectional area that } \\
\text { necessitates long bracing for } \\
9 \text { months) }\end{array}$ & $\begin{array}{l}\text { F (Soft tissue dystrophy and } \\
\text { need walking brace for } \\
9 \text { months) }\end{array}$ \\
\hline 3 & $\mathrm{E}$ & G (Soft tissue dystrophy) \\
\hline 4 & $\mathrm{G}(\operatorname{LLD} 5 \mathrm{~cm})$ & $\mathrm{E}$ \\
\hline 5 & $\mathrm{E}$ & $\mathrm{E}$ \\
\hline 6 & $\mathrm{E}$ & G (Soft tissue dystrophy) \\
\hline 7 & $\mathrm{E}$ & $\mathrm{E}$ \\
\hline 8 & $\mathrm{E}$ & E \\
\hline 9 & $\mathrm{G}(\mathrm{LLD} 4 \mathrm{~cm})$ & $\begin{array}{l}\mathrm{G} \text { (Need walking brace for } \\
10 \text { months) }\end{array}$ \\
\hline 10 & $\mathrm{E}$ & $\mathrm{E}$ \\
\hline 11 & $\mathrm{E}$ & $\begin{array}{l}\mathrm{G} \text { (Loss of }>20^{\circ} \text { knee } \mathrm{ROM} \\
\text { from the presenting range) }\end{array}$ \\
\hline 12 & Missed case & \\
\hline 13 & $\mathrm{E}$ & $\mathrm{E}$ \\
\hline 14 & $\mathrm{E}$ & $\mathrm{E}$ \\
\hline 15 & $\mathrm{E}$ & $\begin{array}{l}\mathrm{G} \text { (Loss of }>20^{\circ} \text { knee } \mathrm{ROM} \\
\text { from the presenting range) }\end{array}$ \\
\hline 16 & $\mathrm{P}$ (Nonunion) & $\begin{array}{l}\mathrm{P} \text { (Marked limitation of daily } \\
\text { activity) }\end{array}$ \\
\hline 17 & $\mathrm{E}$ & $\mathrm{E}$ \\
\hline 18 & $\mathrm{E}$ & $\mathrm{G}$ (Need for walking aid) \\
\hline 19 & $\mathrm{E}$ & $\mathrm{E}$ \\
\hline 20 & E & $\begin{array}{l}\mathrm{G} \text { (Loss of }>20^{\circ} \text { knee } \mathrm{ROM} \\
\text { from the presenting range) }\end{array}$ \\
\hline
\end{tabular}

$E$ excellent result, $G$ good result, $F$ fair result, $P$ poor result

$[11,12]$ but where the distal rings are replaced by femoral arches.

From a patient's perspective of fixator tolerability and comfort, this fixator conveniently spares encircling the medial aspect of the patient's thigh with bulky rings. From a biomechanical point of view, it is a versatile semicircular multiplanar device. It allows for frequent compression of the fracture site postoperatively when fracture site resorption is observed. The mechanical axis of the femur lies outside the bone itself and medial to its anatomical axis. Axial loading on the femoral head will create compression forces on its medial side and a tensile force on the lateral side. Consequently, stable fixation of a femoral diaphyseal fracture is accomplished if, provided that inherent bone stability (through fracture site bone contact) was obtained first, a sufficiently rigid external fixator is applied laterally and is sufficient to act as a tension band fixation [5, 10, 26-28].

Inherent bone stability and bone contact, especially of the medial cortex, are of utmost importance for fixation stability that enables the patient to weight bear early. Bone contact increases the effective diameter of the fracture to obtain a good cross-sectional area of bone at the future union site $[5,22,29]$. This was achieved using different ways of squaring off the bone ends and occasional use of supplemental minimal osteosynthesis (interfragmentary screws) to stabilise unstable oblique fractures or with structural grafts to fill a partial circumferential bone defect if this was $>1 / 3$ diameter of the femur.

Concomitant bone lengthening for cases with infected nonunion of the femur has been reported to carry significant complications [20,30]. These findings were also reported again by Blum et al. in 2010 [30]. This suggests deferring lengthening - if required - to a second stage after achieving full fracture consolidation and recovery of the patient's physical, functional and psychological status. It should be reserved for those who are able to cope with the strenuous combined treatment protocols of external fixation and lengthening. Fortunately, it has been reported that patients may tolerate shortening well up to $2 \mathrm{~cm}$ without the need for a shoe lift and, for those with up to $4 \mathrm{~cm}$ shortening, comply well with a shoe lift of $2 \mathrm{~cm}[31,32]$.

The final results presented in this consecutive series are comparable with those from similar studies [2-4, 20, 33]. The mean time in the fixator was 11.2 months and is comparable to other published works $[2-4,20]$. The prevalence of knee stiffness is not always a complication of the use external fixation but is related to other factors such as the fracture location, the extent of soft tissue damage, pre-exiting stiffness and the severity and duration of infection [3]. The limitations of this study include the absence of a control group and the small cohort of patients but this attributable to the restriction in the inclusion criteria to preserve group homogeneity.

\section{Conclusion}

A semi-circular external fixator module which is entirely half-pin based is described, which is shown to be patient tolerable and effective for managing infected nonunion of the femoral diaphysis.

Conflict of interest The authors declare no conflict of interest; there is no financial support was received for this study, and this work was not supported by any mean.

Open Access This article is distributed under the terms of the Creative Commons Attribution License which permits any use, distribution, and reproduction in any medium, provided the original author(s) and the source are credited.

\section{References}

1. Ricci WM, Gallagher B, Haidukewych GJ (2009) Intramedullary nailing of femoral shaft fractures: current concepts. J Am Acad Orthop Surg 17(5):296-305 
2. Krishnan A, Pamecha C, Patwa JJ (2006) Modified Ilizarov technique for infected nonunion of the femur: the principle of distraction-compression osteogenesis. J Orthop Surg (Hong Kong) 14(3):265-272

3. Ueng SW, Wei FC, Shih CH (1999) Management of femoral diaphyseal infected nonunion with antibiotic beads local therapy, external skeletal fixation, and staged bone grafting. J Trauma 46(1):97-103

4. Saridis A, Panagiotopoulos E, Tyllianakis M, Matzaroglou C, Vandoros N, Lambiris E (2006) The use of the Ilizarov method as a salvage procedure in infected nonunion of the distal femur with bone loss. J Bone Jt Surg [Br] 88-B:232-237

5. Khanfour AA, Zakzouk SA (2012) Distal femur non-union after interlocked intramedullary nailing. Successful augmentation with wave plate and strut graft. Acta Orthop Belg 78(4):492-499

6. Grivas TB, Magnissalis EA (2011) The use of twin-ring Ilizarov external fixator constructs: application and biomechanical proofof principle with possible clinical indications. J Orthop Surg Res 6:41

7. Moss DP, Tejwani NC (2007) Biomechanics of external fixation: a review of the literature. Bull NYU Hosp Jt Dis 65(4):294-299

8. Fenton P, Phillips J, Royston S (2007) The use of Ilizarov frames in the treatment of pathological fracture of the femur secondary to osteomyelitis: a review of three cases. Injury 38(2):240-244

9. Kishan S, Sabharwal S, Behrens F, Reilly M, Sirkin M (2002) External fixation of the femur: basic concepts. Tech Orthop 17(2):239-244

10. Fragomen AT, Rozbruch SR (2007) The mechanics of external fixation. HSS J 3(1):13-29

11. Green SA, Harris NL, Wall DM, Ishkanian J, Marinow H (1992) The Rancho mounting technique for the Ilizarov method. A preliminary report. Clin Orthop Relat Res 280:104-116

12. Belhan O, Ekinci A, Karakurt L, Yllmaz E, Serin E (2008) The treatment of femoral shaft fractures in adults with hybrid Ilizarov external fixator. Jt Dis Rel Surg 19(2):50-54

13. Cavusoglu AT, Ozsoy MH, Dincel VE, Sakaogullari A, Basarir K, Ugurlu M (2009) The use of a low-profile Ilizarov external fixator in the treatment of complex fractures and non-unions of the distal femur. Acta Orthop Belg 75:209-218

14. Benedetti GB, Argnani F (1991) Group. ASAMI. Fractures of the femur. In: Maiocchi AB, Aronson J (eds) Operative principles of Ilizarov fracture treatment-nonunion-osteotomies-lengthening-deformity correction. Williams and Wilkins, Baltimore, Hong Cong, London, Sydney, pp 125-145

15. Baran O, Havitcioglu H, Tatari H, Cecen B (2008) The stiffness characteristics of hybrid Ilizarov fixators. J Biomech 41(14):2960-2963

16. Mahran MA, Elgebeily MA, Ghaly NA, Thakeb MF, Hefny HM (2011) Pelvic support osteotomy by Ilizarov's concept: is it a valuable option in managing neglected hip problems in adolescents and young adults? Strateg Trauma Limb Reconstr 6(1):13-20
17. Catagni MA (2003) Atlas for the insertion of transosseous wires and half-pins Ilizarov method. 2nd. ed. Melan-Italy: Il quadratinoItaly; p. 23-29

18. Paley D, Catagni MA, Argnani F, Villa A, Benedetti GB, Cattaneo R (1989) Ilizarov treatment of tibial nonunions with bone loss. Clin Orthop Relat Res 241:146-165

19. Paley D, Maar DC (2000) Ilizarov bone transport treatment for tibial defects. J Orthop Trauma 14(2):76-85

20. Barbarossa V, Matkovic BR, Vucic N, Bielen M, Gluhinic M (2001) Treatment of osteomyelitis and infected non-union of the femur by a modified Ilizarov technique: follow-up study. Croat Med J 42(6):634-641

21. Bronson DG, Samchukov ML, Birch JG, Browne RH, Ashman RB (1998) Stability of external circular fixation: a multi-variable biomechanical analysis. Clin Biomech (Bristol, Avon) 13(6):441-448

22. Karaharju EO, Aalto K (1983) The deformation of external fixation devices during loading. Int Orthop 7(3):179-183

23. Willie B, Adkins K, Zheng X, Simon U, Claes L (2008) Mechanical characterization of external fixator stiffness for a rat femoral fracture model. J Orthop Res 27:687-693

24. Pugh KJ, Wolinsky PR, Pienkowski D, Banit D, Dawson JM (1999) Comparative biomechanics of hybrid external fixation. J Orthop Trauma 13(6):418-425

25. Lenarz C, Bledsoe G, Watson J (2008) Circular External Fixation Frames with Divergent Half Pins. A Pilot Biomechanical Study. Clin Orthop Relat Res 466:2933-2939

26. Baruah RK (2007) Ilizarov methodology for infected non union of the Tibia: classic circular transfixion wire assembly vs. hybrid assembly. Indian J Orthop 41(3):198-203

27. Sabharwal S, Kishan S, Behrens F (2005) Principles of external fixation of the femur. Am J Orthop 34(5):218-223

28. Sabharwal S (2005) Role of Ilizarov external fixator in the management of proximal/distal metadiaphyseal pediatric femur fractures. J Orthop Trauma 19(8):563-569

29. Khalily C, Voor M, David S (1998) Fracture Site Motion with Ilizarov and "Hybrid" external fixation. J Orthop Trauma 12(1):21-26

30. Blum AL, BongioVanni JC, Morgan SJ, Flierl MA, dos Reis FB (2010) Complications associated with distraction osteogenesis for infected nonunion of the femoral shaft in the presence of a bone defect: a retrospective series. J Bone Jt Surg Br 92(4):565-570

31. Rose R (2009) Complications of Femoral Lengthening using the Ilizarov Fixator. Internet J Orthopedic Surg 15(1):1-6

32. Benedetti M, Catani F, Benedetti E, Berti L, Gioia A, Giannini S (2010) To what extent does leg length discrepancy impair motor activity in patients after total hip arthroplasty? Int Orthop 34:1115-1121

33. Struijs PA, Poolman RW, Bhandari M (2007) Infected nonunion of the long bones. J Orthop Trauma 21(7):507-511 